\title{
The clinico-etiological profile of febrile seizure and its association with serum ferritin level
}

\author{
Gautam S. ${ }^{1}$, Singh P.P. ${ }^{2}$, Barman S. K. ${ }^{3}$, Arya A. K. ${ }^{4}$ \\ ${ }^{1}$ Dr. Shailendra Gautam, Associate Professor, Department of Pediatrics, Government Medical College, Jalaun, \\ ${ }^{2}$ Dr. Pir Pratap Singh, JR-3, Department of Pediatrics, GSVM, Kanpur, ${ }^{3}$ Dr. Santosh Kumar Barman, Associate Professor \\ Department of Community Medicine, Government Medical College, Banda, ${ }^{4}$ Dr. Arun Kumar Arya, Professor, \\ Department of Pediatrics, Department of Pediatrics, GSVM, Kanpur, India.
}

Corresponding Author: Dr. Shailendra Gautam, Associate Professor, Department of Pediatrics, Government Medical College, Jalaun Email: njmsonline@gmail.com

\begin{abstract}
Background: Febrile seizures are defined as an event in infancy or childhood, usually occurring between 6 months and 5 years of age, associated with fever but without evidence of intracranial infection or other definable cause Thus, the present study was conducted to determine any association between serum ferritin level and first febrile seizure. Methods: A cross sectional study was conducted among the infants of age group 6 month to 5 year with complaints of fever with seizures attending Department of Pediatrics, GSVM Medical College, Kanpur for Feb. 2017 to Oct. 2018. After approval from Institutional Ethics Committee. Data was collected on pre deign case sheet consisting of general information history, clinical examination, temperature recording and relevant laboratory investigation such as hemoglobin, total leucocyte count, differential leucocyte count and serum ferritin levels. Statistical analysis was done using SPSS (version 24.0; SPSS Inc., Chicago, IL, USA). Results: Study found that among 50 children, $40 \%$ children of febrile seizure belonged to age group 1 year to 2 years; febrile seizure was predominantly present in male population. Type of febrile seizure was predominantly simple febrile seizure (72\%) and complex febrile seizure (28\%). Results of GTCS it clearly indicate that there is statically significant association of GTCS with low serum ferritin level of less than $10 \mathrm{ng}$. Conclusions: In ferritin less than $10 \mathrm{ng}, 29(90.6 \%)$ patients had GTCS and which was statistically significant. Association of cause of fever vs. serum ferritin was statistically significant. Larger studies are needed to confirm the present findings.
\end{abstract}

Keywords: Febrile seizure, Serum ferritin, Association

\section{Introduction}

Febrile seizures are seizures that occur between the age of 6 and 60 months with a temperature of 380C $(100.40 \mathrm{~F})$ or higher, that are not the result of central nervous system infection and that occur in the absence of a history of prior afebrile seizures. A simple febrile seizure is a primary generalized and tonic-clonic in nature, lasts a few seconds and rarely up to $15 \mathrm{~min}$, is followed by a brief postictal period of drowsiness, and occurs only once in 24 hours [1,2].

The incidence of febrile convulsions is $2-5 \%$ in neurologically healthy child. The peak incidence of febrile seizure is at the age of 14 to 18 months [2]. Iron

Manuscript received: $18^{\text {th }}$ June 2019

Reviewed: $28^{\text {th }}$ June 2019

Author Corrected: $4^{\text {th }}$ July 2019

Accepted for Publication: $9^{\text {th }}$ July 2019 deficiency anemia is one of the most prevalent micronutrient deficiencies in young children in India and other parts of the world, and it is strongly associated with persistent cognitive and motor delays even after the anemia and iron deficit have been repaired. Most iron in neonates is in circulating hemoglobin.

As the relatively high hemoglobin concentration of the newborn infant falls during the first 2-3 months of life, considerable iron is recycled. These iron stores are usually sufficient for blood formation in the first 6-9 months of life in term infants. In term infants, anemia is caused solely by inadequate dietary iron usually occurs at 9-24 months of age and is relatively uncommon thereafter $[3,4]$. Iron deficiency anemia was defined as 


\section{Original Research Article}

the $\mathrm{Hb}$ concentration falls 2 standard deviation (SD) below the mean for age as presence of the indexes. Serum iron concentration $430 \mathrm{mcg} / \mathrm{dl}$ in children, confirm this status $[1,2,4]$. Owing to their association with epilepsy in future, various studies have attempted to identify the risk factors associated with them viz, family history of febrile seizures, epilepsy, perinatal factors and temperature peak. Pisacane, et al. reported that low iron level is associated with febrile seizure, whereas Kobrinsky, et al. reported that iron deficiency raises the threshold for seizures $[5,6]$.

As iron is important for function of neurotransmitters and various enzymes, low level of serum ferritin may lower the seizure threshold [7]. Fever can worsen the negative effects of low serum ferritin on the brain and trigger seizure [5]. Considering the age prevalence of iron deficiency anaemia and febrile convulsion which are the same, the role of iron in the metabolism of neurotransmitters (such as GABA and serotonin) and some enzymes (such as monoaminoxidase and aldehideoxidase), the function of hemoglobin in conveying oxygen to the brain and since fever can exacerbate symptoms that result from anaemia, a relationship between iron deficiency anaemia and febrile convulsions is probable. This study was conducted to determine any association between serum ferritin level and first febrile seizure.

\section{Material and Methods}

To conduct the present cross-sectional hospital based study, atotal of 50 children were studied in the Department of Pediatrics, GSVM Medical College, Kanpur for Feb. 2017 to Oct. 2018 following setting were made and most standard methods were applied.

Inclusion criteria: The study group comprised of children having febrile seizure in age group 6 month to 5 year.

\section{Exclusion criteria}

a) Consist of children between age group 6 month to 5 year. Through history taking, clinical examination and routine investigation were done to exclude any disease condition conformation of the fact that the children have not suffered in past from any condition such as meningitis, any convulsion, encephalitis and other neurological illness.

b) The study group comprised of cases of seizure, having temperature at least $37.8^{\circ} \mathrm{C}$ within emergency department as in history within age group 6 month to 5 yrs all cases having CNS infection like meningitis, encephalitis, serum electrolyte imbalance and other acute neurological illness, or that of drug containing elemental supplement as with other condition known to alter serum ferritin levels are excluded from the study.

Tools of data collection: After approval from Institutional Ethics Committee data was collected on pre deign case sheet consisting of general information history, clinical examination, temperature recording and relevant laboratory investigation such as hemoglobin, total leucocyte count, differential leucocyte count and serum ferritin levels.

Statistical Analysis: For statistical analysis data were entered into a Microsoft excel spreadsheet and then analyzed by SPSS (version 24.0; SPSS Inc., Chicago, IL, USA) and Graph Pad Prism version 5. Data had been summarized as mean and standard deviation for numerical variables and count and percentages for categorical variables without other qualification, 'chisquared test' often is used as short for Pearson's chisquared test.

Unpaired proportions were compared by Chi-square test or Fischer's exact test, as appropriate. P-value $\leq 0.05$ was considered for statistically significant.

\section{Results}

Table-1: Age wise distribution of Serum ferritin levels.

\begin{tabular}{|c|c|c|c|}
\hline Serum ferritin & 10ng-300ng & $<\mathbf{1 0} \mathbf{~ n g}$ & Chi-square value; p-value: \\
\hline Age & $8(44.0)$ & $8(25.0)$ & \\
\hline 6 month -1year & $6(33.3)$ & $14(43.8)$ & \multirow{2}{*}{$10.0694 ; 0.0393$} \\
\hline 1- 2 years & $0(0.0)$ & $8(25.0)$ & \\
\hline 2- 3years & $2(11.1)$ & $2(6.3)$ & \\
\hline 3- 4years & $2(11.1)$ & $0(0.0)$ & \\
\hline 4- 5years & &
\end{tabular}




\section{Original Research Article}

Table 1 shows that 8(44.4\%) patients aged between 6 months-1year 6(33.3\%) patients aged between 1-2 years, 2(11.1\%) patients aged between 3-4years and 2(11.1\%) patients aged between 4-5yearshad serum ferritin level of 10ng-300ng). While $8(25.0 \%)$ patients who were aged between 6 months-1year, 14(43.8\%) patients aged between 1-2 years, 8(25.0\%) patients aged between 2-3 years and 2(6.3\%) patients aged between 3-4years had serum ferritin level $<10$ ng. Association of age and serum ferritin was found to be statistically significant $(\mathrm{p}=0.0393)$ (Table 1).

Table-2: Gender wise distribution of Serum Ferritin levels.

\begin{tabular}{|c|c|c|c|}
\hline \multicolumn{5}{|c|}{ Serum Ferritin } \\
\cline { 1 - 3 } Gender & 10ng-300ng & $<\mathbf{1 0} \mathbf{~ n g}$ & Chi-square value; p-value: \\
\hline Male & $14(77.8)$ & $21(65.6)$ & $0.8102 ; 0.3680$ \\
\hline Female & $4(22.2)$ & $11(34.4)$ & \\
\hline
\end{tabular}

Table 2 shows that among patients with Serum ferritin levels10ng-300ng, 14(77.8\%) were males and 4(22.2\%) were females while among patients with serum ferritin levels $<10 \mathrm{ng}, 21(65.6 \%)$ were males and $11(34.4 \%)$ were females. Association of gender and serum ferritin was not statistically significant $(\mathrm{p}=0.3680)$ (Table 2$)$

Table-3: Association of type of Seizure with Serum Ferritin levels

\begin{tabular}{|c|c|c|c|}
\hline \multicolumn{2}{|l|}{ Serum Ferritin } \\
\hline Type of seizure & $\mathbf{1 0 n g - 3 0 0 n g}$ & $<\mathbf{1 0} \mathbf{~ n g}$ & Chi-square value;p-value: \\
\hline GTCS & $7(38.9)$ & $29(90.6)$ & \multirow{2}{*}{$15.2950 ;<0.0001$} \\
\hline Focal & $11(61.1)$ & $3(9.4)$ & \\
\hline
\end{tabular}

Table 3 shows that in ferritin 10ng-300ng, 7(38.9\%) patients had GTCS and 11(61.1\%) patients had focal seizure. In ferritin $<10 \mathrm{ng}, 29(90.6 \%)$ patients had GTCS and 3(9.4\%) patients had focal seizure. Association of type of seizure vs. serum ferritin was statistically significant $(\mathrm{p}<0.0001)($ Table 3$)$

Table-4: Distribution of causes of fever according to Serum Ferritin levels.

\begin{tabular}{|c|c|c|c|}
\hline \multicolumn{2}{|l|}{ Serum Ferritin } & <10 ng & Chi-square value;p-value: \\
\hline Cause of fever & $\mathbf{1 0 n g - 3 0 0 n g}$ & $10(31.3)$ & \multirow{2}{*}{$8.2610 ; 0.0409$} \\
\hline Respiratory & $6(33.3)$ & $16(50.0)$ & \\
\hline GIT & $4(22.2)$ & $2(6.3)$ & \\
\hline UTI & $0(0.0)$ & $4(12.5)$ & \\
\hline Other & $8(44.4)$ &
\end{tabular}

Table 4 shows that in ferritin 10ng-300ng, 6(33.3\%) patients had respiratory, 4(22.2\%) patients had GIT and 8(44.4\%) patients had other cause of fever. In ferritin $<10 \mathrm{ng}, 10(31.3 \%)$ patients had respiratory, 16(50.0\%) patients had GIT, $2(6.3 \%)$ patients had UTI and 4(12.5\%) patients had other cause of fever. Association of cause of fever vs serum ferritin was statistically significant $(\mathrm{p}=0.0409)$ (Table 4).

\section{Discussion}

Febrile seizures are the most common type of seizures, occurring in 3 to $4 \%$ of children [8]. Various studies have attempted to identify the risk factors associated with them viz, age gender, family history of febrile seizures, epilepsy, perinatal factors and temperature peak. Pisacane, et al. [5] reported that low iron level is associated with febrile seizure, where as Kobrinsky, et al[6] reported that iron deficiency raises the threshold for seizures. The present study was conducted on 50 children of between age group 6 month to 5 years from with febrile seizure. Found that among 50 children, $40 \%$ children of febrile seizure belonged to age group 1 year to 2 year (Mean 17.4 \pm SD 5.3 months) similar result was shown in study of Moruskar et al[9], 62.6\%, Potdar et al[10] age $(18.9 \pm 9.01)$ and Ghosal et al[11] $51.7 \%$ no study showing result different then the present study with respect to incidence of febrile seizure in age group of 1 year to 2 year. 


\section{Original Research Article}

Alfredo Piscane et al [5] found the mean age for FS was 15 months. Separate studies done by Vasvani et al [15], Waruiru et al[16] and Daoud et al[17] also found that FS peaks at 18 months. Naveed-urRehmann et al[13] found mean age was $22.97 \pm 9.52$ months. Susan et al [18] found average age of $39 \pm 15.92$ months. It is generally noted that the febrile convulsion are more common in second year.

Moreover, Febrile seizure was predominantly present in male population $70 \%$ in the present study, similar result was found in study of Moruskar et al[9] 71.76\% and Potdar et al[10] 60.1\% and Ghoshal et al[11] majority of cases were male $(66.7 \%)$ no study showing result different then the present study with respect to predominance of febrile seizure in males Type of febrile seizure was predominantly simple febrile seizure (72\%) and complex febrile seizure $(28 \%)$ in the present study ,similar result was found in study of Moruskar et al[9] simple febrile seizure $(69.41 \%)$ and complex febrile seizure $(30.59 \%)$ and Potdar et al[10] simple febrile seizure (80.2\%) and complex febrile seizure(19.2\%) no study showing result different then the present study with respect to type of febrile seizure.

Regardless of the era of the study or particulars of the design; boys have consistently emerged with higher frequency of febrile seizures. Incidence ratios of boys: girls have ranged from 1.1:1 to $2: 1$ according to Nelson and Ellenberg [19], however in the present study; findings are in contrast to another set of large studies by Verity et al [20] 1985 who found no sex difference. Amir Salari also found no gender difference between cases and controls. NCPP study showed male predilection only among black population [19] whether there is a biological basis for the gender specific differences in febrile seizure susceptibility or whether boys just contract more fevers and therefore are at greater risk, is currently not established.

Type of febrile seizure was predominantly simple febrile seizure $(72 \%)$ and complex febrile seizure $(28 \%)$ in the present study, similar result was found in study of Moruskar et al[9] simple febrile seizure (69.41\%) and complex febrile seizure $(30.59 \%)$ and Potdar et al[10] simple febrile seizure (80.2\%) and complex febrile seizure(19.2\%) no study showing result different then the present study with respect to type of febrile seizure. Serum ferritin level was found less than the range 10ng in $64 \%$ of population, within the range $(10-300 \mathrm{ng})$, in $36 \%$ of population, no one had serum ferritin level more than range (300 $\mathrm{ng}$ ) in the study population of febrile seizure similar result was seen in study of
Potdar et al[10], Ghoshal et al[11], Fallah et al[12], Rehman et al[13]'Bidabadi et al[14] shows serum ferritin level more than $300 \mathrm{ng}$ in study population of febrile seizure. Family history in children having serum ferritin level 10-300 ng6(33.3\%) had positive family history seizure where has in children having serum ferritin level of less than $10 \mathrm{ng} 10(31.3 \%)$ had positive family history having association seizure so serum ferritin level with family history is not statically significant ( $\mathrm{p}$ value .87 )

In addition, Zareifar et al [21] indicated that in Shiraz, Iran, iron deficiency (56.6\% vs. 24.8\%) was more frequent in children with FS and in the FS group; $\mathrm{Hb}$ levels were lower than in febrile children without seizure. Akbayram et al [22] indicated that in Turkey, in children with FS, serum iron levels were lower than in the healthy children group. Kumari et al [23] indicated that in India, in FS children, iron deficiency was more frequent than in febrile children without seizure. In another Indian study, the mean of serum ferritin levels were significantly lower in FS children than in children with febrile illness but without convulsion[24].

Sherjil et al[25] indicated that in Pakistan, in children with FS, iron deficiency anemia was more frequent than in febrile children without seizures $(31.58 \%$ vs. $19.6 \%)$. In a study conducted in Islamabad, children with FS had hemoglobin, hematocrit, and serum ferritin level that were significantly lower than in febrile children without seizures [13]. In a Canadian study, iron deficiency $(9 \%$ vs. $5 \%$ ) and iron deficiency anemia (6\% vs. $4 \%$ ) were more frequent in children with FS and the odds ratio for iron deficiency in patients with FS was 1.84[26]. In present study children with serum ferritin level of less than $10 \mathrm{ng} 29(90.6 \%)$ had GTCS where as $3(9.4 \%)$ had focal seizure in children with serum ferritin level of 10 - $300 \mathrm{ng}, 11(61.1 \%)$ had focal seizure and 7 (38.9\%) had GTCS it clearly indicate that there is statically significant association of GTCS with low serum ferritin level of less than $10 \mathrm{ng}$.

\section{Conclusion}

Age, association of type of seizure (GTCS versus Focal) and cause of fever were significantly related to serum ferritin levels. Larger studies are needed to confirm the findings.

\section{Author's contribution}

First and second author were major contributor in the collection of data and planning of study, while third and fourth author helped in compilation of data. 


\section{Original Research Article}

\section{What this study adds to existing knowledge?}

Present study adds that association of type of seizure (GTCS versus Focal) and serum ferritin levels have a significant relationship.

Funding: Nil, Conflict of interest: None initiated, Perission from IRB: Yes

\section{References}

1. Johnston MV. Febrile seizure. In: Behrman RE. Nelson textbook of Pediatrics, Philadelphia: Sunders; 2004: 1994-95.

2. Srinivasa S, Reddy SP. Iron deficiency anemia in children with simple febrile seizures - a cohort study. Curr Pediatr Res. 2014;18(2): 95-98.

3. Gencer H, Kafadar I, Kose G, Yildirmak Y. Relationship of Febrile Convulsion with Iron Deficiency Anemia and Zinc Deficiency. J Acad Res Med. 2016; 6 (2):94-7.

4. Kumari PL, Nair MK, Nair SM, et al. Iron deficiency as a risk factor for simple febrile seizures--a case control study. Indian Pediatr. 2012 Jan; 49(1):17-9. Epub 2011 May 30.

5. Pisacane A, Sansone R, Impagliazzo N, Coppola A, Rolando P, D' Apuzzo A, et al. Iron deficiency anemia and febrile convulsion: Case control study in children under 2 years. BMJ 1996; 313: 343.

6. Kobrinsky NL, Yager JY, Cheang MS, et al. Does iron deficiency raise the seizure threshold? J Child Neurol. 1995 Mar; 10(2):105-9. DOI: 10.1177/08830 7389501000207

7. Oski FA, Honig AS. The effects of therapy on the developmental scores of iron-deficient infants. J Pediatr. 1978 Jan; 92(1):21-5. DOI:10.1016/s0022-3476 (78) $80063-8$

8. Johnston MV. Seizures in childhood: Febrileseizures. In: Behrman RE, Kliegman RM, JensonHB, editors. Nelson's Textbook of Pediatrics. 17thed. Pennsylvania: Saunders; 2004. p. 1994-1995

9. Moruskar $\mathrm{AD}$ et al; Prospective study of iron deficiency status in febrile seizure patients at tertiary hospital Sangli. International $\mathbf{J}$ of Health care and biomedical research. 2016; 4 (3); 40-48.
10. Potdar PS. Study of some epidemiological aspects of seizure disorders among children in rural of district. Int J Community Med Public Health .2018; 5: 2888-93.

11. Ghoshal S, Reynolds AS, Claassen J. Cyclic seizures- A clue to seizure termination? Clin Neurophysiol. 2017 Jun; 128 (6):1034-1036. DOI: 10. 1016 /j. clinph. 2017.02.014. Epub 2017 Mar 2.

12. Fallah R, Tirandazi B, Akhavan Karbasi S, et al. Iron deficiency and iron deficiency anemia in children with febrile seizure. Iran J Ped Hematol Oncol. 2013; 3(1):200-3. Epub 2013 Jan 22.

13. Naveed-ur-Rehman1, Billoo AG. Association between iron deficiency anemia and febrile seizures. J Coll Physicians Surg Pak. 2005 Jun;15(6):338-40. DOI: 06.2005/JCPSP. 338340

14. Bidabadi E, Mashouf M. Association between iron deficiency anemia and first febrile convulsion: A casecontrol study. Seizure. 2009 Jun;18(5):347-51. DOI: 10.1016/j.seizure.2009.01.008. Epub 2009 Feb 15.

15. Vaswani RK, Dharaskar PG, Kulkarni S, et al. Iron deficiency as a risk factor for first febrile seizure. Indian Pediatr. 2010 May;47(5):437-9. Epub 2009 Sep 3.

16. Waruiru C, Appleton R. Febrile seizures: an update. Arch Dis Child. 2004 Aug; 89(8):751-6. DOI:10.1136/ adc. 2003.028449

17. Doud AS, Batiena A, Abu-Ekteish F. Eplipsia 2002 Jul; 43 (7): 740-3.

18. Susan A S, Keihani Doust Zarrin Taj, Mostafa A, Amin S, Zohreh K, Shahla A, Torkaman M, Yasaman G. Relationship between iron deficiency anaemia and febrile seizures. Iran J Child neurology 4(1); 2010: 27-30

19. Nelson KB, Ellenberg JH. Prognosis in children with febrile seizures. Pediatrics. 1978 May;61(5):720-7.

20. Verity CM, Golding J. Risk of epilepsy after febrile convulsions: A national cohort study. BMJ. 1991 Nov 30; 303(6814): 1373-1376.

21. Zareifar S, Hosseinzadeh HR, Cohan N. Association between iron status and febrile seizures in children. Seizure. 2012 Oct; 21(8): 603-5. DOI: 10.1016/j. seizure. 2012. 06.010. Epub 2012 Jul 15. 


\section{Original Research Article}

22. Akbayram S, Cemek M, Büyükben A, et al. Major and minor bio-element status in children with febrile seizure. Bratisl Lek Listy. 2012;113(7):421-3.

23. Kumari PL, Nair MK, Nair SM, et al. Iron deficiency as a risk factor for simple febrile seizures--a case control study. Indian Pediatr. 2012 Jan; 49(1):17-9. Epub 2011 May 30.

24. Vaswani RK, Dharaskar PG, Kulkarni S, et al. Iron deficiency as a risk factor for first febrile seizure. Indian Pediatr. 2010 May; 47(5):437-9. Epub 2009 Sep 3.
25. Sherjil A, us Saeed Z, Shehzad S, et al. Iron deficiency anaemia--a risk factor for febrile seizures in children. J Ayub Med Coll Abbottabad. 2010 Jul-Sep; 22 (3):71-3.

26. Hartfield DS, Tan J, Yager JY, et al. The association between iron deficiency and febrile seizures in childhood. Clin Pediatr (Phila). 2009 May; 48 (4): 4206. doi: 10.1177/ 0009922809331800. Epub 2009 Feb 19.

\section{How to cite this article?}

Gautam S, Singh P.P, Barman S. K, Arya A. K. The clinico-etiological profile of febrile seizure and its association with serum ferritin level. Int J Pediatr Res. 2019;6(07):331-336.doi:10. 17511/ijpr. 2019.i07.04 